\title{
Diosmin Phytosomes: Development, Optimization and Physicochemical Characterization
}

\author{
Prachi P Udapurkar*, Omprakash G Bhusnure, Santosh R Kamble \\ School of Pharmacy, Swami Ramanand Teerth Marathwada University, Nanded - 431606, Maharashtra, INDIA.
}

\begin{abstract}
Background: Diosmin is a flavonoids glycoside that possesses different therapeutic activity include vascular-protecting agent used to help improving chronic venous insufficiency (CVI), haemorrhoids, etc. Diosmin is bioactive flavones constituent with wide range of biological activity. The poor solubility and dissolution rate limit its oral absorption and bioavailability. Aim: The aim of the present study is to develop diosmin phospholipid complex (DN-PC) and characterized by physicochemical method. Method: DN-PC was prepared by refluxing followed by solvent evaporation technique in different ratios of Diosmin to Phosphatidylcholine. Physicochemical Characterization: DN-PC was characterised by various parameters like drug content, solubility studies, particle size determination, infrared absorption (FTIR), Differential scanning calorimetry (DSC), $X$-ray diffraction (XRD), Scanning electron microscopy (SEM), entrapment efficiency etc. Results: SEM and XRD revealed the reduction in crystallinity of diosmin in the phytosomes. FTIR and DSC confirm the formation of phyto-phospholipid complex. Conclusion: The results of the study revealed that the phospholipid complex may be considered as a promising drug delivery system that improves the absorption and bioavailability of plant constituents.
\end{abstract}

Key words: Phytosome, Diosmin, Phophatidyl choline, Characterization.

\section{INTRODUCTION}

The therapeutic uses of phytoconstituents are very popular for health maintenance by various means. Most of the bioactive constituents of plants are polar or water-soluble molecules (e.g. phenolics, glycosides, tannins and flavonoids). However, water soluble phytoconstituents are limited in their effectiveness because they are poorly absorbed due to large molecular size and poor lipid solubility when taken orally or when applied topically. ${ }^{1}$

Flavonoids are beneficially effective for antioxidant, anti-inflammatory, antiviral, antiallergic, anticancer, etc. ${ }^{2}$ The chemical structures and physicochemical properties of flavonoids verify their rate and extent of absorption. The biological activities of flavonoids depend on their bioavailability. The very limited information is available about bioavailability of flavonoids. ${ }^{3-4}$
Diosmin is flavonoid glycoside that can be isolated from various plant sources or derived from the flavonoid hesperidins. ${ }^{5}$ Diosmin is considered to be a vascularprotecting agent used to help improving chronic venous insufficiency (CVI), ${ }^{6}$ haemorrhoids, lymphedema, and varicose veins. ${ }^{7}$ As a flavonoid, diosmin also exhibits antiinflammatory, ${ }^{8}$ free-radical scavenging, ${ }^{9}$ antidiabetic ${ }^{10}$ and antimutagenic properties. ${ }^{11}$ The diosmin is practically insoluble in water. ${ }^{12}$ Thus the dissolution rate of diosmin is limiting its absorption from the gastrointestinal tract. An attempt was made to increase the oral bioavailability of the drug chiefly centred on particle size reduction. The rate and extent of dissolution of diosmin was increase by nano sizing which led directly to an increase oral bioavailability which in turn enables dosage reduction.
Submission Date: 30-01-2018; Revision Date: 13-04-2018; Accepted Date: 17-05-2018

DOI: 10.5530/ijper.52.4s.73 Correspondence: Prachi P. Udapurkar, Research Scholar School of Pharmacy, Swami Ramanand Teerth Marathwada University, Nanded - 431606 Maharashtra, INDIA. Phone: +919423113050 E-mail: prachi.udapurkar@ gmail.com

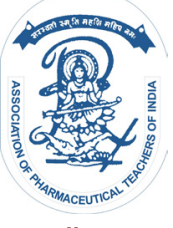

www.ijper.org 
The therapeutic dose of diosmin is $500 \mathrm{mg}$ twice daily which is very high, thus it is necessary to be administered frequently in order to maintain the normal therapeutic concentration of diosmin. ${ }^{13}$

The phytosome technique has emerged as one of the leading methods of improving bioavailability of phyto-pharmaceuticals having poor competency of solubilising and crossing the biological membranes. ${ }^{14}$ Phytosome is a patented technology of Indena where plant polyphenolics are complexed with phospholipids to improve bioavailability. ${ }^{15-20}$ Phospholipids are lipid molecules where glycerol is bonded to two fatty acids. Phospholipid mainly phosphatidylcholine, are lipophilic substances and readily form complex with polyphenolic compounds. Phosphatidylcholine is a major structural constituent of all biological membranes. Phosphatidylcholine is a major component of soybean lecithin which provides free choline in the blood for the manufacture of acetylcholine; regulates digestive, cardiovascular and liver functions. ${ }^{21}$

Diosmin shows low bioavailability because it is not soluble in water and is rapidly eliminated from the body. The aim of this study is to develop a diosmin loaded phospholipid complex that could have potential to increase the bioavailability. The key objective of the present study is to develop the phytosome of diosmin, to increase the solubility and bioavailability of drug, to prepare the diosmin phytosome by specific method. The complex (DN-PC) thus prepared was evaluated physico-chemically for drug loading, chemical interaction (FT-IR), thermal analysis (DSC), crystallinity (X-RPD) surface morphology (SEM), solubility and dissolution rate study. The developed complex may be suitable to reduce the dose and frequency and hence reduce toxic or side effect of diosmin.

\section{MATERIALS AND METHODS}

\section{Materials}

Diosmin was purchased from Sigma Aldrich, Mumbai (India). Phosphatidylcholine and dimethyl sulfoxide was purchased from Ozone international, Mumbai. All other chemicals and reagents were of analytical grade.

\section{Methods}

\section{Preparation of Diosmin Phospholipid complex (DN-PC)}

DN-PC was prepared by refluxing followed by solvent evaporation technique. ${ }^{22} \mathrm{DN}-\mathrm{PC}$ was prepared in different ratios, i.e., $0.5: 1,0.75: 1,1: 1,2.5: 1$ and $3: 1$ of Diosmin to Phosphatidylcholine. Diosmin and Phosphatidylcholine were dissolved in Dimethylsulphoxide (DMSO) and dichloromethane respectively. Both the solutions were mixed and pour in a $200 \mathrm{ml}$ round bottomed flask. The mixture was refluxed for 3-4 $\mathrm{h}$ and at various temperature $45-65^{\circ} \mathrm{C}$. After $3 \mathrm{~h}$ the mixture was cooled and then poured to Petri dish. The dish was kept open overnight at room temperature for evaporation of solvent. Then the product was kept in hot air oven at $60^{\circ} \mathrm{C}$ for $2 \mathrm{~h}$. The dried DN-PC were gathered and stored in desiccators for further use.

\section{Design of Experiment}

A response surface design was used to study the influence of independent variables, viz., drug: phospholipids ratio $\left(\mathrm{X}_{1}, \mathrm{w}: \mathrm{w}\right)$, and temperature $\left(\mathrm{X}_{2},{ }^{\circ} \mathrm{C}\right)$ on the entrapment efficiency of diosmin. The two independent variables $\left(\mathrm{X}_{1}\right.$ and $\left.\mathrm{X}_{2}\right)$ were selected at three levels resulting in thirteen possible combinations. The dependent variable is entrapment efficiency of diosmin. The experimental trials were performed using all thirteen possible combinations of the selected variables. The mathematical model containing coefficient effects, interactions, and polynomial terms was analyzed to assess the response using the following equation:

$\mathrm{Y}=\mathrm{b}_{0}+\mathrm{b}_{1} \mathrm{X}_{1}+\mathrm{b}_{2} \mathrm{X}_{2}-\mathrm{b}_{3} \mathrm{X}_{1} * \mathrm{X}_{1}-\mathrm{b}_{4} \mathrm{X}_{2}^{*} \mathrm{X}_{2}-\mathrm{b}_{5} \mathrm{X}_{1} * \mathrm{X}_{2}$ Where $\mathrm{Y}$ is the dependent variable, $\mathrm{b}$ is the coefficient of the independent variable $\mathrm{X}$. The main effects $\left(\mathrm{X}_{1}\right.$ and $\mathrm{X}_{2}$ ) represent the possible aggregate effect of both factors as they change independently from their low to high level. The interaction term $\left(\mathrm{X}_{1} \mathrm{X}_{2}\right)$ shows how the response changes when two factors are simultaneously changed. The polynomial terms describes the nonlinearity. The design levels and the real values of the independent variables are shown in Table 1. The composition of experimental trials along with obtained yield (\%) values is shown in the Table 2.

\section{Characterization of DN-PC complex Apparent Solubility}

The apparent solubility was determined by adding excess of DN and DN-PC complexes to $5 \mathrm{ml}$ of water or $\mathrm{n}$-octanol in sealed glass containers at room temperature $\left(25-30^{\circ} \mathrm{C}\right)$. The liquids were agitated for $24 \mathrm{~h}$ then centrifuged for $20 \mathrm{~min}$ at $1,000 \mathrm{rpm}$ to remove excessive DN or DN-PC complex. The supernatant was filtered through a membrane filter $(0.45 \mathrm{~m})$ then $1 \mathrm{ml}$ filtrate was dilute with $9 \mathrm{ml}$ of distilled water and absorbance were measured at $268 \mathrm{~nm}$ using UV spectrophotometer. ${ }^{23-24}$

\section{Entrapment Efficiency}

Entrapment efficiency (EE) was measured using UVvisible spectrophotometer (UV-1601, Shimadzu). A 


Table 1: Coded level and real values for each factor
under study.
\begin{tabular}{|c|c|c|c|c|c|}
\hline \multirow{2}{*}{ Variables } & \multicolumn{5}{|c|}{ Levels } \\
\cline { 2 - 6 } & $-\mathbf{1 . 4 1}$ & -1 & $\mathbf{0}$ & $\mathbf{1}$ & $\mathbf{1 . 4 1}$ \\
\hline $\mathrm{X} 1$ & 0.5 & 1.0 & 1.75 & 2.5 & 3.0 \\
\hline $\mathrm{X} 2$ & 45 & 50 & 55 & 60 & 65 \\
\hline
\end{tabular}

\begin{tabular}{|c|c|c|c|}
\hline Formulation & $x_{1}$ & $\mathrm{x}_{2}$ & $\begin{array}{l}\text { Entrapment efficiency } \\
(\% \mathrm{w} / \mathrm{w})\end{array}$ \\
\hline 1 & 1 & 50 & $72.72 \pm 1.5$ \\
\hline 2 & 2.5 & 50 & $88.21 \pm 0.3$ \\
\hline 3 & 1 & 60 & $84.51 \pm 1.6$ \\
\hline 4 & 2.5 & 60 & $87.36 \pm 0.9$ \\
\hline 5 & 0.5 & 55 & $89.52 \pm 1.3$ \\
\hline 6 & 3 & 55 & $86.41 \pm 1.1$ \\
\hline 7 & 1.75 & 45 & $83.23 \pm 1.2$ \\
\hline 8 & 1.75 & 65 & $96.32 \pm 1.4$ \\
\hline $9-13$ & 1.75 & 55 & $94.36 \pm 1.0$ \\
\hline
\end{tabular}

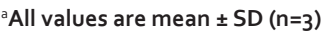

weighed quantity of phyto-phospholipid complex DN-PC equivalent to $10 \mathrm{mg}$ of diosmin was added to $50 \mathrm{ml}$ methanol in a $100 \mathrm{ml}$ beaker. The contents were stirred on a magnetic stirrer for $4 \mathrm{~h}$ and then allowed to stand for one hour. Clear liquid was decanted and centrifuged at $5000 \mathrm{rpm}$ for $15 \mathrm{~min}$. After centrifugation the supernatant was filtered through $0.45 \mu$ whatman filter paper and after suitable dilution absorbance was measured in UV at $268 \mathrm{~nm}$; the concentration of drug was measured. ${ }^{25}$ All measurements were performed in triplicate. The EE (\%) was calculated using the following formula:

$$
\mathrm{EE}(\%)=\mathrm{T}-\mathrm{S} / \mathrm{T} \times 100
$$

Where, T-Total concentration of diosmin, S-is the diosmin contained in the filtrate.

\section{Particle size distribution}

The particle size analysis of the prepared DN-PC sample was carried out using photon correlation spectroscopy, with dynamic light scattering on Zetasizer nano (Model: Nano series, S90 Zeta sizer, Malvern) The complex was dispersed in isopropyl alcohol by stirring on a magnetic stirrer for $10 \mathrm{~min}$. The dispersion was analysed in size analyser.

\section{X-Ray diffraction (XRD) study}

Diffractometer (Bruker, Germany) was used for measurements of the studied samples. The operating conditions were: voltage $45 \mathrm{kV}$; current $0.8 \mathrm{~mA}$; scanning speed $1 / \mathrm{min}$. The results were recorded over a range of $5-60^{\circ}(2 \theta)$ using the $\mathrm{Cu}$-Anode $\mathrm{X}$-ray tube and scintillation detector.

\section{Differential scanning calorimetry (DSC)}

DSC studies for pure DN and DN-PC were performed on a Perkin Elmer (USA) (Model JADE DSC) differential scanning calorimeter by heating samples over a temperature range of $50-300^{\circ} \mathrm{C}$ in closed metal pans at the rate of $10^{\circ} \mathrm{C}$ per min under the environment of nitrogen gas.

\section{Fourier Transform Infrared spectroscopy (FTIR) Study}

FT-IR studies were performed on pure DN, PC, physical mixture (PM) and DN-PC was in an Alpha FTIR spectrophotometer IR Affinity-1 (Shimadzu Corporation). A small quantity of sample was placed just below the probe on to which the probe was tightly fixed and scanned in the wave number region 4000-500 $\mathrm{cm}^{-1}$. The obtained IR spectra were interpreted for functional groups at their respective wave number $\left(\mathrm{cm}^{-1}\right)$.

\section{Scanning electron microscopy (SEM)}

$\mathrm{DN}$ and DN-PC were coated with gold in a Fine Coat Ion Sputter S-4800 TYPE II, Hitachi high technologies corporation, Japan. Analysis was done on the coated sample by placing a pinch of sample in the S-4800 TYPE II (Hitachi high technologies corporation, Japan) Scanning electron microscope and surface morphology was viewed and photographed.

\section{Dissolution Study (in-vitro Drug Release)}

The in vitro dissolution profiles of $\mathrm{DN}$, physical mixture (PM) and the prepared DN-PC were obtained and compared. ${ }^{26}$ The dissolution studies were carried out in a USP XXIII, six station dissolution test apparatus, type II (VEEGO Model No. 6 DR, India) at $100 \mathrm{rpm}$ and at $37^{\circ} \mathrm{C}$. An accurately weighed amount of DN-PC of diosmin $50 \mathrm{mg}$ was put in to $900 \mathrm{ml}$ of $\mathrm{pH} 6.8$ phosphate buffer. Samples (3 $\mathrm{ml}$ each) of dissolution fluid were withdrawn at different time intervals and replaced with an equal volume of fresh medium to maintain sink conditions. Withdrawn samples were filtered (through a $0.45 \mu \mathrm{m}$ membrane filter), diluted suitably and then analyzed spectrophotometrically at $268 \mathrm{~nm}$ to determine drug release from the complex and the drug. 


\section{RESULT AND DISCUSSION}

\section{Preparation of DN-PC complex}

The initial investigation of the influence of factors revealed that all the studied factors, i.e., the drug to phospholipids ratio and temperature had a significant influence on the entrapment efficiency of the prepared phytosome. The results of the entrapment efficiency $(\%)$ are shown in Table 2 . The measured values from the experimental trials revealed wide range (72.72-96.32, $\% \mathrm{w} / \mathrm{w}$ ) entrapment efficiencies (Table 2). The fitted polynomial equations relating the response (entrapment efficiency, $\% \mathrm{w} / \mathrm{w}$ ) to the transformed factors are shown in Figure 1. The polynomial equations could be used to draw conclusions after considering the magnitude of the coefficient, and its associated mathematical sign, i.e., positive or negative. The results from Figure 1 also indicated that all the coefficients were statistically significant $(\mathrm{p}<0.05)$. The value of correlation coefficient $\left(\mathrm{R}^{2}\right)$ was found to be 0.9522 indicating a good fit to the quadratic model. The multiple regression analysis revealed that the coefficients were positive. This indicated that the entrapment efficiency increased with increasing $\mathrm{X}_{1}$ and $\mathrm{X}_{2}$.

$$
\begin{gathered}
Y=-206+66.5 X_{1}+8.07 X_{2}-5.50 X_{1} * X_{1}-0.0545 \\
X_{2} * X_{2}-0.825 X_{1}^{*} X_{2}
\end{gathered}
$$

Based on the central composite design and response surface plots depicting the changes in the entrapment efficiency (\%) as a function of $\mathrm{X}_{1}$ and $\mathrm{X}_{2}$. The data from all 13 batches of the central composite design were used for generating interpolated values using Minitab software. The response surface plots and contour plot (Figure 1) indicated a strong influence of the studied factors on entrapment efficiency. Increasing levels of $\mathrm{X}_{1}$ and $\mathrm{X}_{2}$ were found to be favorable conditions for obtaining higher entrapment efficiency. Based on these observations, along with calculations from the developed quadratic model, the optimal values for the studied variables, i.e. drug: phospholipids ratio $\left(\mathrm{X}_{1}\right.$, w: w) and the reaction temperature $\left(\mathrm{X}_{2},{ }^{\circ} \mathrm{C}\right)$ were found to be $1: 1$ and $65^{\circ} \mathrm{C}$ respectively.

\section{Validation of model}

An additional batch of DN-PC was prepared in order to validate the model using the optimized values of the variables, i.e. $\mathrm{X}_{1}$ and $\mathrm{X}_{2}, 1: 1$ and $65^{\circ} \mathrm{C}$ respectively. $\mathrm{A}$ comparison between the predicted (theoretical) value $(\%)$ of the DN-PC obtained from the developed model and the observed value $(\%)$ achieved from the prepared formulation was carried out. The model-predicted value for the entrapment efficiency of diosmin in DN-PC was $95.38 \%$, while the average observed value (\%) from the prepared batches was found to be $94.08 \pm 0.67$,

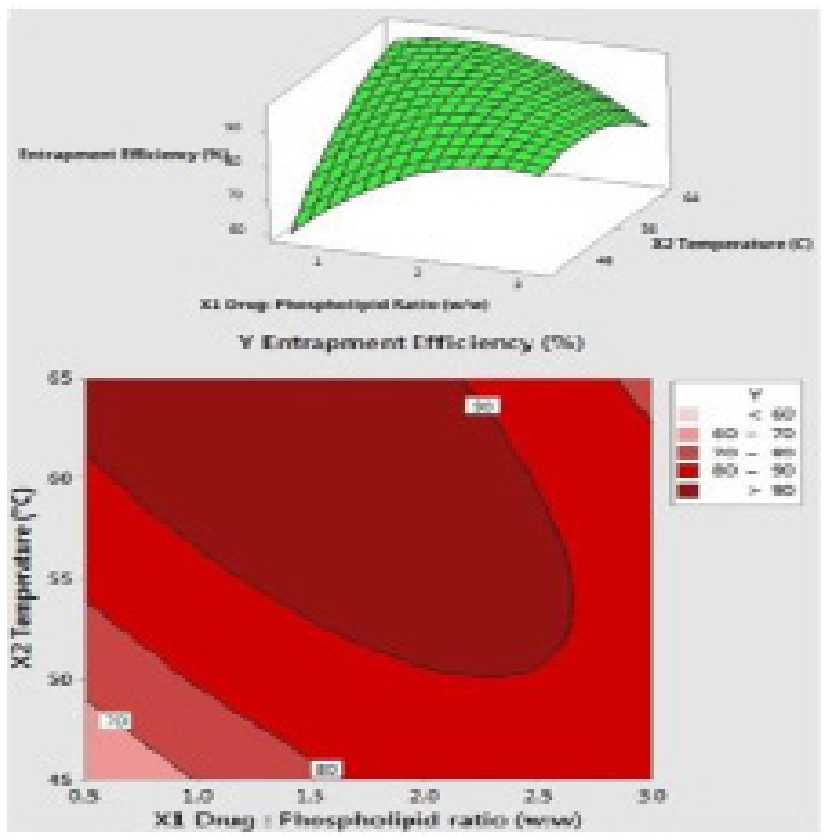

Figure 1: The response surface plot and contour plots of entrapment efficiency $(\mathrm{Y}, \%)$ as a function of the ratio of Diosmin to Phospholipid (X1, w: w), and the reaction temperature $\left(\mathrm{X} 2,{ }^{\circ} \mathrm{C}\right)$.

Table 3: Observed and predicted value of entrapment efficiency prepared under optimal protocol.

\begin{tabular}{|c|c|c|c|}
\hline Batches & $\begin{array}{c}\text { Predicted value } \\
(\%)\end{array}$ & $\begin{array}{c}\text { Observed value } \\
\text { (\%) }^{\text {a }}\end{array}$ & Bias \\
\hline 1 & 95.38 & $94.23 \pm 0.14$ & 1.48 \\
\hline 2 & 95.38 & $94.87 \pm 1.53$ & 0.53 \\
\hline 3 & 95.38 & $95.19 \pm 0.34$ & 2.8 \\
\hline
\end{tabular}

${ }^{a}$ All values are mean \pm SD $(n=3)$

Table 4: Apparent solubility study of DN, PM and DNPC in water and n-octanol.

\begin{tabular}{|c|c|c|c|}
\hline SN & Sample & $\begin{array}{c}\text { Aqueous Solubility } \\
(\mu \mathrm{g} / \mathrm{mL})^{\text {a }}\end{array}$ & $\begin{array}{c}\text { n-Octanol } \\
\text { solubility }(\boldsymbol{\mu g} / \mathbf{m L})^{\text {a }}\end{array}$ \\
\hline 1 & DN & $4.35 \pm 0.34$ & $305.65 \pm 0.54$ \\
\hline 2 & PM & $8.12 \pm 1.35$ & $432.21 \pm 0.04$ \\
\hline 3 & DN-PC & $80.32 \pm 0.13$ & $617.34 \pm 0.58$ \\
\hline
\end{tabular}

${ }^{\text {aAll values are mean } \pm S D(n=3)}$

(Table 3) indicating both applicability, and validity of the developed model. The bias (\%), calculated using the equation, was also found to be less than $3 \%(1.35 \%)$, indicating the relative robustness of the model.

\section{Physico-chemical characterization of prepared CP Apparent Solubility of CP}

The results of the measured apparent solubility of the pure DN, the physical mixture of $\mathrm{DN}$ and $\mathrm{PC}$, and the prepared DN-PC complex are shown in Table 4. It was 
observed that the pure diosmin had poor aqueous solubility $(4 \mu \mathrm{g} / \mathrm{mL})$, and a relatively higher solubility in $\mathrm{n}$-Octanol $(305 \mu \mathrm{g} / \mathrm{mL})$, indicating a rather lipophilic nature of the drug. The physical mixture (PM) revealed a non-significant change in the n-Octanol solubility and a modest increase (1.5 times) in the aqueous solubility. The prepared DN-PC, however, showed a dramatic, and a significant (over 12-fold) increase in the aqueous solubility. This increase in the solubility of the prepared complex may be explained by the partial amorphization (reduced molecular crystalline) of the drug, and the overall amphiphilic nature of the Phytosome..$^{27-28}$

\section{Particle size distribution:}

The mean particle size of the prepared DN-PC was carried out using dynamic light scattering technique. The mean particle size of DN-PC was distributed in a narrow range of $233.4 \pm 20.0 \mathrm{~nm}$, and polydispersity index was $0.642 \pm 0.03$. The surface area/volume $(\mathrm{SA} / \mathrm{V})$ ratio of most particles is inversely proportional to the particle size. Thus, smaller particles of the DN-PC, having a higher $\mathrm{SA} / \mathrm{V}$, make it easier for the entrapped drug to be released from the phytosome via diffusion and surface erosion. They also have the added advantage for the drug entrapped phytosomes to penetrate into, and permeate through the physiological drug barriers. LeFevre et al. and Savic et al. have previously suggested that larger particles $(\leq 5 \mathrm{~mm})$ are taken up via the lymphatics, while the smaller particles $(\leq 500 \mathrm{~nm})$ can cross the epithelial cell membrane via endocytosis. ${ }^{29-31}$

\section{X-Ray diffraction (XRD) study}

The x-ray diffraction (PXRD) patterns of (A) DN, (B) PC, (C) PM, and (D) DN-PC. The diffractogram of the DN (Figure 3) revealed sharp crystalline peaks at $2 \theta=46.9^{\circ}, 43.5^{\circ}, 36.6^{\circ}$, and $28.0^{\circ}$. A diffraction peak was observed for $\mathrm{PC}$ at $35.5^{\circ}, 36.4^{\circ}$, and $25.2^{\circ}$. The physical mixture (PM) showed most of the peaks associated with the DN and PC (Figure 3C). In comparison to the physical mixture, the diffractogram of the DN-PC revealed the disappearance of most of the crystalline peaks associated with the DN. These results were in agreement with the previously reported studies, where the disappearance of the active pharmaceutical ingredient (API) peaks was associated with the formation of drug phospholipid complex. ${ }^{32}$ The disappearance of diosmin crystalline peak confirms the formation of diosmin- phospholipid complex. ${ }^{33}$

\section{Scanning electron microscopy (SEM)}

SEM photographs give important insight into the solid state properties and surface morphology of DN and DN-PC. In the Figure 4 (A) the shows crystalline

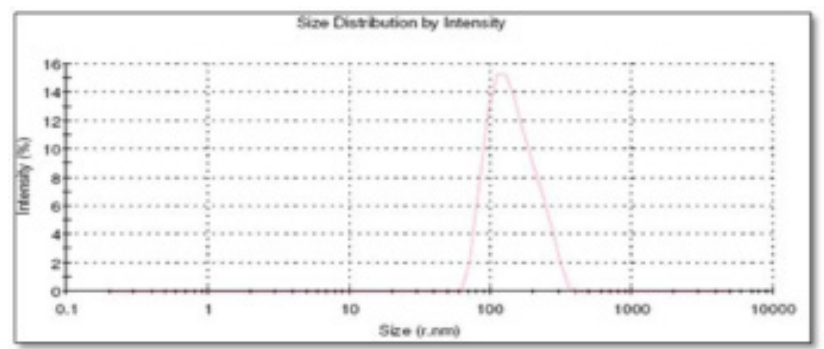

Figure 2: Particle size analysis of DN-PC.

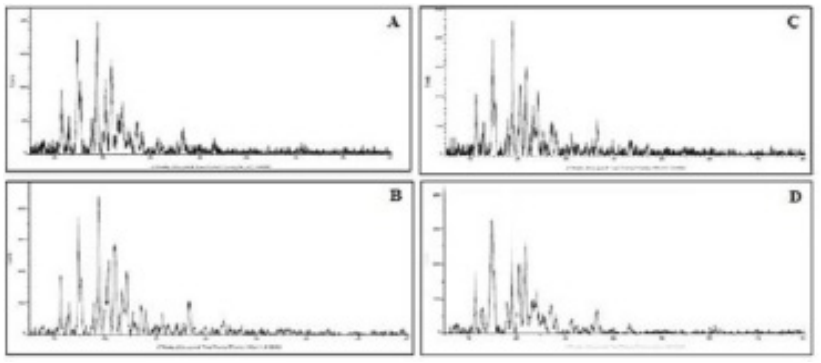

Figure 3: XRD spectra of (A) DN, (B) PC, (C) PM and (b) DN-PC.

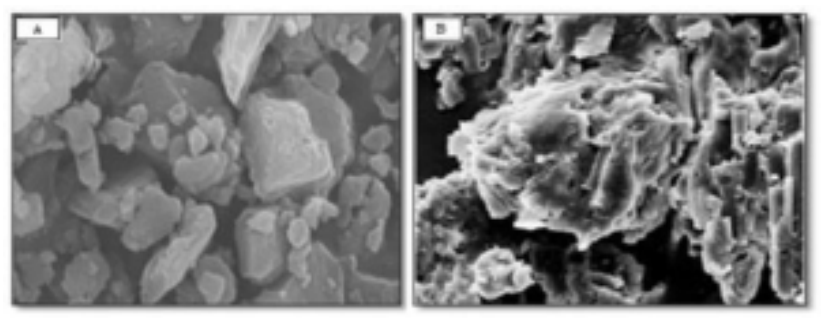

Figure 4: SEM of DN (A) and DN-PC (B).

state of DN was visualized in the SEM photograph as numerous crystals. In Figure 4 (B) drug was completely converted in to phyto-phospholipid (DN-PC) complex where DN was physically enwrapped by PC imparting amorphous nature to the complex due to which crystals disappeared.

\section{FT-IR study}

The results from the Fourier transform infrared spectroscopy (FTIR) analyses of the DN, PC, the physical mixture of DN with PC (PM), and the prepared DN-PC were studied in order to get insight into occurrence of interaction between DN and PC. The FTIR spectrum of DN (Figure 5A) exhibited a broad peak at $3556 \mathrm{~cm}^{-1}$, representing the aliphatic alcoholic $(-\mathrm{OH})$ group, $2900 \mathrm{~cm}^{-1}$ (CH stretching), $1660 \mathrm{~cm}^{-1}$ (C=O stretching), $1559 \mathrm{~cm}^{-1}$ ( $\mathrm{C}=\mathrm{C}$ stretching). Prominent peak observed at $1160 \mathrm{~cm}^{-1}$ and $1050 \mathrm{~cm}^{-1}$ typically relates to presence of acidic functional group. FTIR spectrum of PC (Figure 5B) revealed the characteristic absorption at 2921 and $2850 \mathrm{~cm}^{-1}$ (CH stretching), $1775 \mathrm{~cm}^{-1}$ (C=O stretch- 


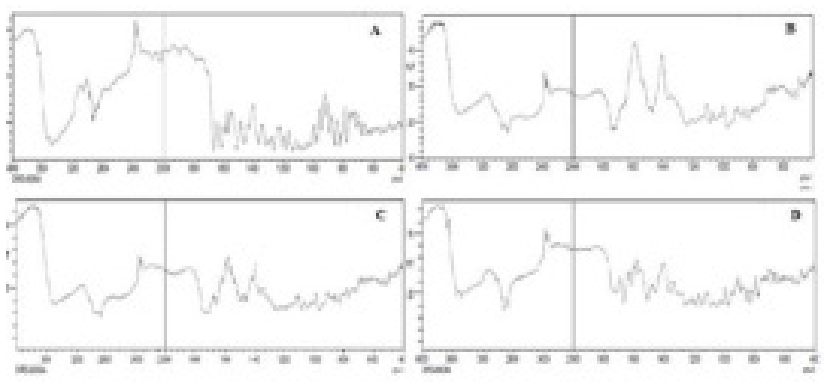

Figure 5: FTIR spectra of (A) DN, (B) PC, (C) Physical mixture and (D) DN-PC.

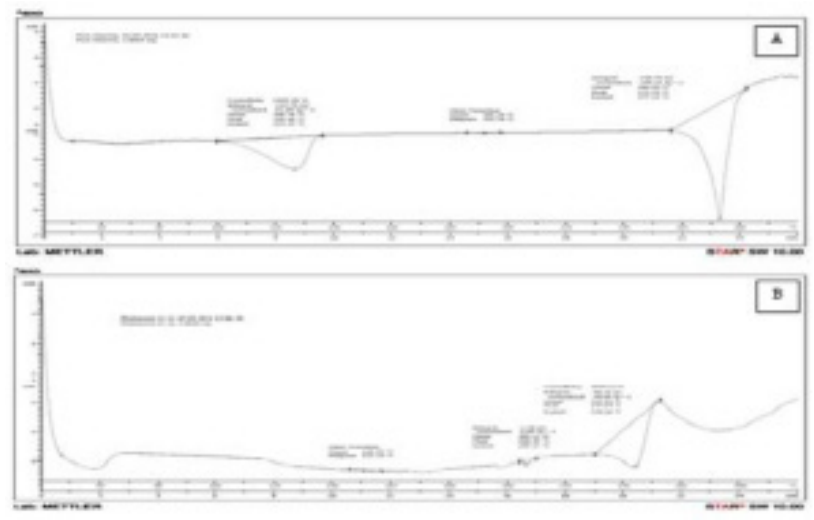

Figure 6: Differential scanning Calorimetry of (A) DN and (B) DN-PC.

ing), $1235 \mathrm{~cm}^{-1}$ ( $\mathrm{P}=\mathrm{O}$ stretching), $1081 \mathrm{~cm}^{-1}$ (P-O-C stretching) and $975 \mathrm{~cm}^{-1}$ (C-C-N stretching). The FTIR spectrum of the prepared DN-PC (Figure 2D) is quite different from that of DN and PC. The peaks at 1660 $\mathrm{cm}^{-1}, 1559 \mathrm{~cm}^{-1}$ and $3556 \mathrm{~cm}^{-1}$ were shielded by phospholipids. The absorption at $1660 \mathrm{~cm}^{-1}$ shifted to lower field in the spectrum of complex, indicating the formation of hydrogen bond and existence of electrostatic interaction between drug and phospholipids.

\section{Differential scanning calorimetry (DSC)}

DSC is a fast, reliable method to investigate the interaction between multiple component and drug excipient compatibility. These interactions are observed as the elimination of endothermic peak, the appearance of new peak, the change in peak shape, onset temperature/ melting point, relative peak area or enthalpy..$^{34,35}$ The $\mathrm{DN}$ revealed broad endothermic peaks at $126.48^{\circ} \mathrm{C}$ and $272.79^{\circ} \mathrm{C}$. The DSC thermo gram of DN-PC showed complex Figure 6 (B) gives two endothermic peaks at $206.40^{\circ} \mathrm{C}$ and $244.54^{\circ} \mathrm{C}$. Therefore from (Figure 6) it was revealed that the shift of endothermic peak at the difference of around $25-30^{\circ} \mathrm{C}$ suggest possible interaction of DN with PC and can account for enhanced entrapment.

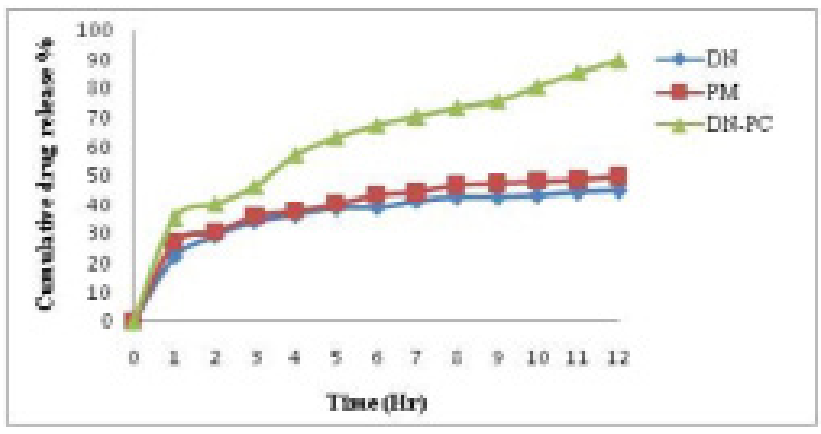

Figure 7: In vitro dissolution study of DN, PM and DN-PC.

\section{Percentage drug release}

The results of in vitro drug release studies are shown in the Figure 7. The 12-h dissolution in the phosphate buffer ( $\mathrm{pH}$ 6.8) revealed that, the pure diosmin showed the slowest rate of dissolution, i.e., at the end of the dissolution period only about $44 \% \mathrm{w} / \mathrm{w}$ of diosmin was dissolved. The dissolution rate of the physical mixture was found not to be significantly different $(\sim 49 \% \mathrm{w} / \mathrm{w}$ dissolved in $12 \mathrm{~h}$ ) compared to the pure diosmin. The prepared DN-PC, revealed a significantly faster release of diosmin at the end of dissolution period. The dissolution profile of the DN-PC at the end of $12 \mathrm{~h}$, over $89 \% \mathrm{w} / \mathrm{w}$ diosmin was observed to be released from the DN-PC. The dissolution rate is largely influenced by the crystal morphology and the wettability of the solids, ${ }^{36}$ and the improved dissolution rate of diosmin from the DN-PC may be explained by the improved solubility, and the partially disrupted crystalline phase (amorphous form) in the prepared complex. The relatively higher amorphous state of the phytosome and their increased water-solubility may have a positive impact on the cumulative release of the drug. ${ }^{37}$

\section{CONCLUSION}

In the present study, an attempt was made to enhance the aqueous solubility of diosmin via its complexation with phospholipids. A central composite design was used to optimize the formulation and process variables. The prepared DN-PC was evaluated for physicochemical and functional attributes. The FTIR, DSC, PXRD, photo microscopy, and the SEM studies indicated the successful formation of vesicular drugphospholipids complex. The apparent solubility, the in vitro dissolution, studies indicated a significant improvement in the aqueous solubility, the drug release, and the membrane permeation of the diosmin from DN-PC respectively. Additional studies analyzing the pharmacokinetic parameters are required to substantiate 
the increased absorption, and the enhanced bioavailability hypothesis.

\section{REFERENCES}

1. Rastija V, Nikoli S, Masand VH. Quantitative Relationships between Structure and Lipophilicity of Naturally Occurring Polyphenols. Acta Chim Slov. 2014;60(4):781-9.

2. Jing L, Xuling W, Ting Z, Chunling W, Zhenjun H. Chemistry and Biological Activities of Flavonoids: An Overview. Scientific World Journal. 2013;1-16.

3. Mahajan RT, Chaudhari GM. A novel approach towards phytosomal flavonoids. Int J Pharm Sci. 2012;3(3):1-15.

4. Kelly EH, Anthony RT, Dennis JB. Flavonoid antiox-idants: chemistry, metabolism and structure-activity relation-ships. J Nutri Biochem. 2002;13(10):572-84

5. Kuntiu V, Brboriu J, Ivanka H, Snezana U. Evaluating the bioactive effects of flavonoid hesperidin - A new literature data survey. Vojnosanit Pregl. 2014;71(1):60-5.

6. Zenovia M, Andrei AB, Mohammed AA, Hassan YA. A Spectrophotometric Method for Diosmin Determination. The Open Chem and Biomed Methods J. 2010;3:123-7.

7. Diosmin monograph, Alt Med Review. 2004;9(3):308-11.

8. Chebil L, Humeau C, Anthoni J, Dehez F, Engasser JM, Ghoul M. Solubility of flavonoid in organic solvents. J Chem and Eng Data. 2007;52(5):1552-6.

9. Freag MS, Elnaggar YS, Abdallah OY. Lyophilized phytosomal nanocarriers as platforms for enhanced diosmin delivery: Optimization and ex vivo permeation. Int J Nanomed. 2013;8:2385-97.

10. Jain D, Bansal MK, Dalvi R, Upganlawar A, Somani R. Protective effect of diosmin against diabetic neuropathy in experimental rats. J Inte Med. 2014;12(1):35-41.

11. Crespo ME, Gálvez J, Cruz T, Ocete MA, Zarzuelo A. Anti-inflammatory activity of diosmin and hesperidin in rat colitis induced by TNBS. Planta Med. 1999;65(7):651-3.

12. Freag MS, Elnaggar YS, Abdallah OY. Development of novel polymerstabilized diosmin nanosuspensions: in vitro appraisal and ex vivo permeation. Int J Pharm. 2013;454(1):462-71.

13. Anwer MK. Development of diosmin loaded eudragit $s 100$ polymeric Nanoparticles: an investigation of antioxidant effect. IJBPAS. 2014;3(8):2015-26.

14. Acharya NS, Parihar GV, Acharya SR. Phytosomes: Novel approach for delivering herbal extract with improved bioavailability. Int $\mathrm{J}$ pharm scien. 2011;2(1):144-60.

15. Tawheed A, Bhat SV. A Review on Phytosome Technology as a Novel approach to improve the Bioavailability of Nutraceuticals. Int J Adv Res and Tech. 2012;3(1):1-15.

16. Udapurkar P, Bhusnure O, Kamble S, Biyani K. Phyto-phospholipid complex vesicles for phytoconstituents and herbal extracts: A promising drug delivery system. Int J Herb Med. 2016;4(5):14-20.

17. Semalty A, Semalty M, Singh M, Rawat M, Franceschi F. Supramolecular phospholipids -polyphenolics interactions: The PHYTOSOME® strategy to improve the bioavailability of phytochemicals. Fitoterapia. 2010;81(5):306-14.

18. Telanga DR, Patil AT, Pethe AM, Tatode AA, Anand S, Dave VS. Kaempferolphospholipid complex: formulation, and evaluation of improved solubility, in vivo bioavailability, and antioxidant potential of kaempferol. J Excipients and Food Chem. 2016;7(4):89-116.
19. Junaid K, Alexander A, Saraf S, Saraf S. Recent advanced and future prospects of phyto-phospholipid complexation technique for improving pharmacokinetic profile of plant actives. J control release. 2013;168(1):50-60.

20. Idhakusumawati Y. Phospholipid Complex as a carrier of Kaempferia Galanga Rhizome extract to improve its analgesic activity. Journal of Pharmacy and Pharmaceutical Sciences. 2011;3(1):44-6.

21. Jing Li, Xuling W, Ting Z, Chunling W, Zhenjun $\mathrm{H}$, Xiang L, et al. A review on phospholipids and their main applications in drug delivery systems. Asian J pharm sci. 2015;10(2):81-98.

22. Malay KD, Bhupen K. Design and Evaluation of Phyto-Phospholipid Complexes (Phytosomes) of Rutin for Transdermal Application. J App Pharm Sci. 2014;4(10):51-7.

23. Devendra SR, Bandana KT, Semalty M, Semalty A, Badoni P, Rawat MS. Baicalein-Phospholipid Complex: A Novel Drug Delivery Technology for Phytotherapeutics. Cur Drug Disc Technol. 2013;10(3):1-9.

24. Xiaoqing C, Yuxia L, Yue J, Aixin S, Wei S, Zhonghao L, et al. Huperzine A-phospholipid complex-loaded biodegradable thermosensitive polymer gel for controlled drug release. Int J of Pharm. 2012;433(1-2):102-11.

25. Damle M, Mallya R. Development and Evaluation of a Novel Delivery System Containing Phytophospholipid Complex for Skin Aging. AAPS Pharm Sci Tech. 2016;17(3):607-17.

26. Saoji SD, Belgamwar VS, Dharashivkar SS, Rode AA, Mack C, Dave VS. The Study of the Influence of Formulation and Process Variables on the Functional Attributes of Simvastatin-Phospholipid Complex. J Pharm Innov. 2016;11(3):264-78.

27. Shrestha H, Bala R, Arora S. Lipid-Based Drug Delivery Systems. J Pharmaceutics. 2014; 1-10.

28. Sovova H. Apparent Solubility of Natural Products Extracted with NearCritical Carbon Dioxide. Am J Anal Chem. 2012;3(12A):958-65.

29. Savic R, Luo L, Eisenberg A, Maysinger D. Micellar nanocontainers distribute to defined cytoplasmic organelles. Science. 2003;300(5619):615-8.

30. Freitas $\mathrm{C}$, Müller $\mathrm{RH}$. Effect of light and temperature on zeta potential and physical stability in solid lipid nanoparticle dispersions. Int $\mathrm{J}$ Pharm. 1998;168(2):221-9.

31. Sahu AN. Development and Characterization of Hepatoprotective Phytosomes of Abutilon Indicum and Piper Longum. Int J Pharm Biol Sciec. 2015;5(4):97-106.

32. Jayanthi $P$, Lalitha P. Reducing power of the solvent extracts of Eichhornia Crassipes. Int J Pharm sci. 2011;3(3):126-8.

33. Jena SK, Singh C, Dora CP, Suresh S. Development of tamoxifenphospholipid complex: Novel approach for improving solubility and bioavailability. Int J Pharm. 2014;473(1-2):1-9.

34. Singh C, Bhatt TD, Gill MS, Suresh S. Novel rifampicin phospholipid complex for tubercular therapy: Synthesis, physicochemical characterization and in-vivo evaluation. Int J Pharm. 2014;460(1-2):220-7.

35. Hai X, Zhen Z, Xin J, Qin H, Xiao C, Xiao J. A novel drug-phospholipid complex enriched with micelles: preparation and evaluation in vitro and in vivo. Int J Nano. 2013;8:545-54.

36. Semalty A, Semalty M, Singh D, Rawat MS. Phytophospholipid complex of catechin in value added herbal drug delivery. J Incl Phenom Macrocycl Chem. 2012;73(1-4):377-86.

37. Vora AK, Londhe VY, Pandita NS. Preparation and characterization of standardized pomegranate extract phospholipid complex as an effective drug delivery tool. J Adv Pharm Tech Res. 2015;6(2):75-80. 
PICTORIAL ABSTRACT

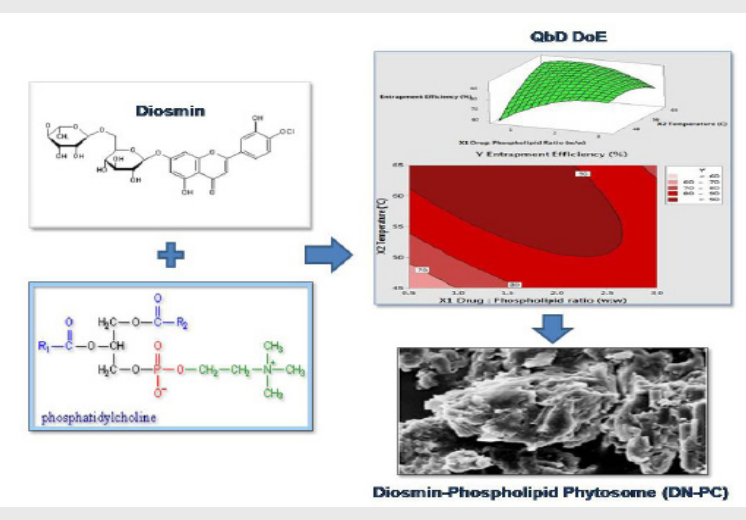

\section{About Authors}

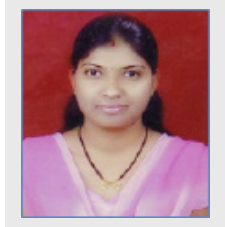

Prachi P Udapurkar: PhD Research scholar at School of Pharmacy, Swami Ramanand Teerth Marathwada University, Nanded. She completed $M$ Pharm in Quality Assurance and DBM from RTM Nagpur University, Nagpur. She worked in the area of pharmaceutical technology and analytical method development.

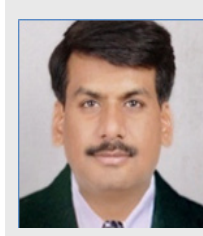

Omprakash G Bhusnure: Is a Professor and Head, Department of Quality Assurance, Swami Ramanand Teerth Marathwada University, Nanded. He completed M. Pharm and PhD in Pharmaceutical Chemistry. He is working on areas of analytical method development, validation, quality by design approach, etc.

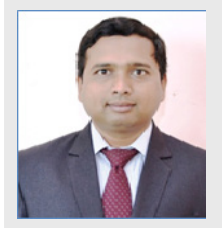

Santosh R Kamble: PhD Research scholar at School of Pharmacy, Swami Ramanand Teerth Marathwada University, Nanded. He is M Pharm in 'Pharmaceutics' and completed Post Graduate Diploma in Patent Law from NALSAR University, Hyderabad. His area of work is formulation \& dosage form technology, novel drug delivery systems, patents \& drug regulatory requirements, etc.

\section{SUMMARY}

- Diosmin is flavonoid glycoside that can be isolated from various plant sources or derived from the flavonoid hesperidins. Diosmin is considered to be a vascular-protecting agent used to help improving chronic venous insufficiency (CVI), haemorrhoids, lymphedema, and varicose veins.

- Diosmin shows low bioavailability because it is insoluble in water and is rapidly eliminated from the body. The phytophospholipid complex of diosmin (DN-PC) was developing to increase the solubility and bioavailability of drug.

- DN-PC was prepared by refluxing followed by solvent evaporation technique. The formulation and the process variables for the preparation of the DN-PC were optimized using a Quality by design $(\mathrm{QbD})$ approach. Response surface design was employed for the optimization of the critical process parameters (CPP) on the diosmin entrapment rate of DN-PC.

- The model-predicted value for the entrapment efficiency of diosmin in DN-PC was $95.38 \%$, while the average observed value (\%) from the prepared batches was found to be $94.08 \pm 0.67$, indicating both applicability, and validity of the developed model.

- The mean particle size of DN-PC was distributed in a narrow range of $233.4 \pm 20.0 \mathrm{~nm}$, and polydispersity index was $0.642 \pm 0.03$. SEM and XRD studies of the diosmin and its phytosome revealed the reduction in crystallinity of diosmin in the phytosomes. FTIR and DSC confirm the formation of phyto-phospholipid complex.

- The prepared DN-PC, revealed a significantly faster release of diosmin at the end of dissolution period. The dissolution profile of the DN-PC at the end of $12 \mathrm{~h}$, over $89 \% \mathrm{w} / \mathrm{w}$ diosmin was observed to be released from the DN-PC.

- The apparent solubility and in vitro dissolution studies indicated a significant improvement in the solubility and the drug release of diosmin (DN) from DN-PC respectively.

Cite this article: Udapurkar PP, Kamble SR, Bhusnure OG, Diosmin Phytosomes: Development, Optimization and Physicochemical Characterization. Indian J of Pharmaceutical Education and Research. 2018;52(4S):S29-S36. 